\title{
LEITURA NUMA PERSPECTIVA DISCURSIVA NA FORMAÇÃO DOCENTE: ALGUNS QUESTIONAMENTOS ${ }^{1}$
}

\author{
Janete Silva dos Santos ${ }^{2}$
}

Resumo: Com base nos pressupostos teóricos da Análise do Discurso, este trabalbo discute, através de alguns questionamentos, a prática de leitura, numa perspectiva discursiva, na formação do professor que atua no Estado de Tocantins, ou seja, reflete sobre leitura como efeito de sentidos, conforme pressupostos teóricos da Análise do Discurso (AD) de linha francesa. O intuito no presente texto, mais que contribuir para o debate da questão, é apontar alguns obstáculos na formação inicial (FI) ou na formação continuada (FC) de professores do nivel básico que podem estar causando entraves em seu entendimento dos Parâmetros Curriculares Nacionais (PCN) e, consequentemente, sua compreensão inadequada do Referencial Curricular do Estado de Tocantins (RC-TO) em relação ao ensino/ aprendizagem de leitura em uma perspectiva mais flexivel, que leve em conta as condições de produção num contexto mais abrangente.

Palavras-chave: Discurso. Leitura e ensino. Formação docente. PCN e RC-TO.

\section{INTRODUÇÃO}

O foco de pesquisas sobre ensino e aprendizagem de leitura no estado do Tocantins, assim como o foi (e ainda tem sido) em outros estados brasileiros com mais tradição em pesquisas nessa área, tem-se intensificado, visto que muitos relatórios de estágio, de estudantes do curso de Letras (UFT), apontam ainda, como recorrente, maior incidência de práticas de leitura como mera decodificação do que se apresenta à superfície textual. Em decorrência disso, problematizamos as referências do professor sobre ensino de leitura numa perspectiva discursiva, conforme informada pelos PCN (BRASIL, 1998), e seu assujeitamento a práticas tradicionais de ensino e aprendizagem de leitura, seja por meio de sua formação inicial (FI), escolar e acadêmica,

\footnotetext{
${ }^{1}$ Este texto é uma reelaboração de parte de minha reflexão sobre leitura na formação docente, feita durante minha pesquisa de doutorado, em Lingüística Aplicada/Unicamp, cuja tese, tematizando modos de assujeitamento, foi defendida no IEL em 2010.

2 Professora Adjunta da Universidade Federal do Tocantins/UFT). Doutora em Linguística Aplicada. Email: janetesantos@uft.edu.br.
} 
seja por meio de sua formação continuada (FC). Por conta disso, também discutimos brevemente nossa própria concepção e prática de ensino de leitura (resultado de nossa reelaboração de discursos teóricos por nós também incorporados), através de uma sucinta mostra de aula, a fim de contribuir com a reflexão do professor que busca ampliar suas possibilidades de incorporar contribuições da Análise do Discurso em sua prática docente.

Assim, o presente texto enfoca mais especificamente a prática de leitura numa perspectiva discursiva, no intuito de discutir e exemplificar, mesmo que de forma breve, leitura como efeito de sentidos, conforme pressupostos teóricos da Análise do Discurso (AD) de linha francesa. Esperamos com isso, mais que contribuir com o debate, apontar, em relação ao professor do ensino básico (não só o tocantinense), alguns entraves que sua FI ou FC podem ter favorecido e/ou estar favorecendo para sua pouca compreensão sobre o que sugerem os Parâmetros Curriculares (PCN) e o Referencial Curricular do Estado do Tocantins (RC-TO) em relação ao ensino/aprendizagem de leitura numa perspectiva mais flexível, que leva em conta as condições de produção num contexto mais abrangente.

\section{LEITURA NA PERSPECTIVA DA AD FRANCESA}

Os pressupostos da Análise do Discurso (AD) francesa, na linha de Pêcheux, definem fatores considerados fundamentais no processo de leitura (construção) de um texto, desencadeadores de sentidos, além do texto em si, ou da relação do leitor com o objeto (texto), ou do autor e leitor, ora dissociados, ora interagindo apenas, como acontece nas concepções de viés sociointeracionista. Para a $\mathrm{AD}$, as condições de produção vão definir os contornos da leitura, o como se lê. Ou seja, ler, numa perspectiva discursiva, vai além da mera ativação do conhecimento prévio ou enciclopédico do leitor (concepção de viés cognitivista), ou de contato entre leitor e texto, leitor e autor, ou da eficaz estratégia textual, usada pelo autor e detectada pelo leitor no texto etc. 
Uma concepção discursiva de leitura reconhece a mobilização de tudo isso e muito mais. Entram em cena, nesse processo, além da relação entre sujeitos (autor e leitor), a relação do inconsciente com a ideologia. Outro fator fundamental, pouco levado em conta em outras abordagens, é a não transparência da linguagem, que desconstrói a ideia de que conseguimos expressar exatamente o que queremos, ao enunciar, e de que qualquer texto pode ser lido do mesmo jeito por qualquer um que domine o código. Ressalte-se, aqui, que, mesmo nos dias de hoje, existem professores de língua materna (LM), de formação purista, que ainda buscam encontrar, nos textos, uma única interpretação possível.

Em contrapartida, o processo de leitura, na perspectiva discursiva, leva ainda em conta os diferentes tipos de discurso, a história de leitura de textos e, também, a história de leitura do leitor (ORLANDI, 1996, p. 38). Desta última, podem-se distinguir duas formas que se cristalizam (ou se mesclam) na formação do leitor: leitura parafrástica (repete o que o autor disse) e/ou leitura polissêmica (atribuição de múltiplos sentidos ao texto). Orlandi (1996) já enfatizava, em página anterior, que essa perspectiva discursiva de leitura

procura observar o processo de sua produção e, logo, da sua significação. Correspondentemente, considera que o leitor não apreende meramente um sentido que está lá; o leitor atribui sentidos ao texto. Ou seja: considera-se que a leitura é produzida e se procura determinar o processo e as condições de sua produção. Daí se poder dizer que a leitura é o momento crítico da constituição do texto... (1996, p. 37)

Isso explica por que as leituras, numa linha discursiva, não são idênticas (ORLANDI, 1996), visto que, como processo comunicativo, a linguagem é histórico-social. Daí que, como exemplifica Orlandi (1996, p. 41), toda leitura tem sua história, pois: "lemos diferentemente um mesmo texto em épocas (condições) diferentes".

Se, por um lado, há sentidos já estabelecidos alhures que afetam a linguagem no aqui/agora, as condições de produção da leitura também podem fazer emergir sentidos novos, pois cada leitor se insere em 
formação(ções) discursiva(s) que o leva(m) a um ou a outro tipo de interação com o dito, circunscrevendo-se em interdiscursos, os já-ditos, a memória discursiva mobilizada a cada enunciação. Orlandi (1996, p. 87) lembra que a pluralidade de leitura "é a possibilidade de se ler um mesmo texto de várias maneiras".

Argumenta ainda a autora que, dentre os componentes das condições de produção da leitura, estão os modos de leitura, que também estabelecem a relação dos leitores com o texto. Assim, conforme $\mathrm{o}(\mathrm{s})$ sentido(s) que se tenta estabelecer durante a leitura, acentua-se o elemento organizador dessa relação, como transcrito a seguir (ORLANDI, 1996, p. 10):

a) O que o autor quis dizer? - relação do texto com o autor (a partir do ponto de vista do leitor)

b) Em que este texto difere de tal texto? - relação do texto com outros textos

c) O que o texto diz de X? - relação do texto com seu referente

d) $\mathrm{O}$ que você entendeu? - relação do texto com o leitor

e) O que é mais significativo neste texto para o professor $Z$ ? $O$ que significa $X$ para o professor Z? - relação do texto com o para quem se lê (se for para o professor)

$\mathrm{Na}$ escola básica, poderíamos reforçar, também, que as estratégias comumente usadas para orientar o olhar dos alunos sobre o texto acabam salientando-se através das perguntas de compreensão (SANTOS, 2001), ou seja, naquilo que o professor e/ou o autor do livro didático (LD) propõem ao aprendiz observar no texto. Os tipos de pergunta acabam "ensinando" ao leitor-aprendiz como se deve ler determinado texto. A rotina dessa prática vai criando uma identidade de leitor para o aprendiz.

O professor, que normalmente utiliza o LD nas atividades de sala de aula, também constrói uma imagem específica para a abordagem dos textos ou mediação que faz junto a seus alunos. Isso porque o LD (seu autor) é visto como quem tem "autoridade" para definir como se deve ler este ou aquele texto (CORACINI, 1999, p. 33-43), por meio das propostas de "reflexão" sobre o texto que apresenta ao leitor-aluno e ao leitor-mediador-professor. 
Vale considerar que, geralmente, o professor, cujo discurso sofre menos deslocamentos, apenas repete o ensino de leitura que recebeu durante sua escolarização obrigatória, isto quando a universidade não conseguiu desestabilizar arraigadas crenças e práticas equivocadas de leitura durante sua formação acadêmica. Como apontam pesquisas coordenadas por Coracini (1995, p. 83; 1999, p. 24), e como mostraram os dados analisados na tese, da qual este artigo é um recorte, mesmo tentando fugir às amarras que o LD lhe impõe, o professor não consegue desestruturar o modo de abordagem do texto, proposto pelo autor. Essa abordagem, em muitas salas de aula, tem se legitimado como portadora da verdade, como veículo transmissor de conhecimento científico, adaptado para o público a que se destina.

Entretanto, se, por um lado, o LD conduz o trabalho na escola, exercendo poder sobre o trabalho do professor, por outro, o professor, nos processos interacionais, controla as trocas enunciativas no espaço da sala de aula. Caso esteja atento ou até mais envolvido com teorias que fogem à tradição do ensino de leitura e escrita, poderá permitir deslocamentos que alterem práticas ineficazes. Segundo Moita Lopes (2001, p. 161), na sala de aula, são "os professores que dizem o que é para ser feito, restando aos alunos um papel restrito ao que deve ser desempenhado".

\section{ALGUMAS ORIENTAÇÕES DOS PCN E DO REFERENCIAL CURRICULAR DO ESTADO DO TOCANTINS (RC-TO) PARA O ENSINO DE LÍNGUA}

Ao ensinar português, na escola, o professor parte de referências escolares e teóricas para ministrar suas aulas de língua portuguesa (LP), seja em relação à seleção de conteúdos, seja em relação ao modo de ensinar. Os documentos da FC do Tocantins também são subsidiados por orientações nacionais, como os PCN (Parâmetros Curriculares Nacionais), que, com algumas modificações, compõem, como paráfrase, também o Referencial Curricular (RC-TO) do Estado, como se pode constatar, abaixo, por um dos excertos extraídos da pesquisa de Silva e Melo (2009, p. 48), quando compara versões de enunciados retirados das orientações dos PCN e das orientações do RC-TO, respectivamente: 
(Excerto 1)

Entretanto, a refacção faz parte do processo de escrita: durante a elaboração de um texto, se relêem trechos para prosseguir a redação, se reformulam passagens. Um texto pronto será quase sempre produto de sucessivas versões. Tais procedimentos devem ser ensinados [grifo dos autores] e podem ser aprendidos. (PCN, 1998, p. 77)

(Excerto 2)

A refacção faz parte do processo de escrita, pois um texto será produto de sucessivas versões, portanto é fundamental que este procedimento seja ensinado de sucessivas versões, portanto é fundamental que este procedimento seja ensinado [grifo dos autores]. O professor deverá destinar um tempo para a atividade de refacção, fornecendo instrumentos lingüísticos para o aluno fazer sua revisão, permitindo-lhe atuar criticamente sobre seu texto. (RC-TO, 2006, p. 249)

Essa alteração mínima no RC do Estado, para língua portuguesa, tem sido questionada por professores da rede pública, visto que, além de já haverem se manifestado, em cursos de Especialização na UFT, contra as "insipientes" orientações didáticas dos PCN, reclamação que se estende por outros estados, conforme acusam algumas pesquisas que tematizam a questão, muitos professores esperavam encontrar nesse documento orientações mais práticas de como ensinar. Isso pode ser conferido, pela especificidade, na pesquisa de Silva e Melo (2009) sobre a construção do referido RC-TO:

Pelo fato dos PCN (Brasil, 1998) não responderem diretamente às demandas da sala de aula e pela exigência oficial de que os Estados tenham suas próprias diretrizes, a Secretaria de Educação e Cultura do Estado do Tocantins publicou o Referencial Curricular de Lingua Portuguesa para o Ensino Fundamental - $1^{\circ}$ ao $9^{\circ}$ ano (Palmas, 2006). A elaboração desse referencial pelos próprios professores da rede estadual de ensino criou uma expectativa de que orientações de "como trabalhar conteúdo em sala de aula" fossem apresentadas, ampliando o espaço da prática escolar na diretriz local que orienta o ensino de língua materna (p. 38). 
Duas questões merecem destaque aqui. A primeira refere-se à carência de reflexão sobre transposição didática, sentida por muitos professores de diversas regiões do país. Afirmamos isso com base também em nossos diálogos com colegas professores que militam no ensino público da escola básica, no Amapá, em Campinas e no próprio Tocantins. Essa carência decerto contribuiu para que, ao serem solicitados a ajudar na construção do RC do Estado, esses profissionais não tenham conseguido imprimir tais reflexões no texto derivado.

Ora, se o RC-TO é considerado pelo próprio professor uma espécie de plágio dos PCN (Silva e Melo, porém, defendem esse trabalho como uma forma de retextualização do texto nacional), e se os PCN, para o professor, pouca informação agregam em relação à transposição didática, na interação teoria/prática, é compreensível sua frustração em relação ao suporte teórico derivado, isto é, ao referencial local. Reproduzimos, abaixo, depoimentos de professores, coletados por Silva e Melo em sua pesquisa (2009, p. 42), que manifestam essa percepção negativa do documento:

Anotação 1

"RC/TO são transgênicos dos PCN, genéricos dos PCN. São como remédios que tanto faz tomar um ou outro que o efeito é o mesmo"

Anotação 2

"A impressão que fica é que o RC/TO é um verdadeiro fichamento dos PCN, ou mesmo um resumo, em que os assuntos não estão amarrados."

Anotação 3

"O RC/TO é uma síntese muito grosseira dos PCN."

As críticas dos professores, em relação às reelaborações dos documentos nacionais feitas nos documentos do Estado, parecem se confirmar também ao se contrapor, por exemplo, enunciados do programa GESTAR II (outro documento nacional) a enunciados do RCTO, versão 2008, como transcritos abaixo, permutando-se, porém, nesta paráfrase, o item lexical comunicativa por discursiva: 
(Excerto 3)

Concepções do Programa

O desenvolvimento da competência comunicativa do aluno, o qual se evidencia na oralidade, na leitura e na produção de textos (GESTAR II, 2008, p. 36-37, grifo nosso)

(Excerto 4)

Portanto, o processo de ensino e aprendizagem da Língua Portuguesa deve

estar voltado para a ampliação da competência discursiva, proporcionando condições de inserção efetiva no mundo da linguagem oral e escrita. (RC-TO, 2008, p. 261, grifo nosso)

Esses questionamentos dos docentes justificariam, assim, algumas contradições nas práticas dos professores, cujos discursos foram por nós analisados, pois ecoam os conflitos por que muitos deles passam. Apesar disso, são essas referências dos PCN que o professor tenta contemplar em suas aulas, ou, no mínimo, são elas que balizam o melhor encaminhamento ou não de seu trabalho com a linguagem. Isso se justifica por se considerar que os produtores de tais parâmetros basearam-se em pesquisas do campo da Linguística Teórica e Aplicada, a fim de orientar, sugerir, alertar o professor sobre o que é, na atualidade, profícuo ou não no ensino da língua materna (LM).

Muitos desses discursos já são conhecidos de professores que se formaram recentemente, entretanto, muitos desses professores estão também mais assujeitados a discursos sobre ensino de língua de sua época escolar, ou seja, aos discursos do ensino tradicional, que são anteriores ao seu período na Universidade, em formação inicial (FI). Logo, é compreensível o embate que se instaura nas práticas docentes em relação ao ensino e aprendizagem de LM, pois, muitas vezes, nem na FI nem na FC se consegue desestabilizar discursos já há muito cristalizados, a fim de que novas e mais eficientes práticas se concretizem.

Em se tratando de ensino de língua portuguesa, ou língua materna, os PCN definem, como objeto de estudo, o conhecimento linguístico e discursivo com o qual o sujeito opera ao participar das práticas sociais mediadas pela linguagem (BRASIL, 1998). Dessa forma, o documento afirma que: 
Ao professor cabe planejar, implementar e dirigir as atividades didáticas, com o objetivo de desencadear, apoiar e orientar o esforço de ação e reflexão do aluno, procurando garantir aprendizagem efetiva. Cabe também assumir o papel de informante e de interlocutor privilegiado, que tematiza aspectos prioritários em função das necessidades dos alunos e de suas possibilidades de aprendizagem. (BRASIL, 1998, p. 22)

De fato, como se observa, o documento, através de orações modalizadoras (cabe ao professor $=$ o professor deve), lança sobre $\mathrm{o}$ professor a responsabilidade de pensar sua aula, conhecer sua matéria, auxiliar seu aluno, fazendo a devida transposição didática, sem exemplificar, ao nível da necessidade e da expectativa do professor, o como fazê-lo. Quanto à seleção do objeto linguístico como unidade básica de ensino, diz o documento que:

não é possível tomar como unidades básicas do processo de ensino as que decorrem de uma análise de estratos letras/fonemas, sílabas, palavras, sintagmas, frases que, descontextualizados, são normalmente tomados como exemplos de estudo gramatical e pouco têm a ver com a competência discursiva. Dentro desse marco, a unidade básica do ensino só pode ser o texto. (BRASIL, 1998, p. 23)

Assim, orientam também os PCN como o texto deve ser tomado, ou seja, de que perspectiva deve ser abordado:

Os textos organizam-se sempre dentro de certas restrições de natureza temática, composicional e estilística, que os caracterizam como pertencentes a este ou aquele gênero. Desse modo, a noção de gênero, constitutiva do texto, precisa ser tomada como objeto de ensino. (BRASIL, 1998, p. 23)

Para essa noção constitutiva do gênero, há mostras de exemplos de gêneros (primários e secundários, orais e escritos) na perspectiva bakhtiniana, que devem ser tomados como objeto de ensino, sendo, porém, o professor orientando a dar maior relevância aos gêneros na modalidade escrita: 
Sem negar a importância dos textos que respondem a exigências das situações privadas de interlocução, em função dos compromissos de assegurar ao aluno o exercício pleno da cidadania, é preciso que as situações escolares de ensino de Língua Portuguesa priorizem textos que caracterizam os usos públicos da linguagem. Os textos a serem selecionados são aqueles que, por suas características e usos, podem favorecer a reflexão crítica, o exercício de formas de pensamento mais elaboradas e abstratas, bem como a fruição estética dos usos artísticos da linguagem, ou seja, os mais vitais para a plena participação numa sociedade letrada (BRASIL, 1998, p. 24).

Apesar de o documento, em parágrafo posterior, pontuar o trabalho com textos orais, deixa em relevância a prioridade dos escritos sobre os orais, esclarecendo em nota o que considera textos de uso público da linguagem:

Por usos públicos da linguagem entendem-se aqueles que implicam interlocutores desconhecidos que nem sempre compartilham sistemas de referência, em que as interações normalmente ocorrem à distância (no tempo e no espaço), e em que há o privilégio da modalidade escrita da linguagem. Dessa forma, exigem, por parte do enunciador, um maior controle para dominar as convenções que regulam e definem seu sentido institucional (BRASIL, 1998, p. 24).

Ao tratar do trabalho com a linguagem no tocante à leitura, um dos objetivos gerais do ensino de língua portuguesa, segundo os PCN (BRASIL, 1998, p. 33), é ensinar o aluno a "analisar criticamente os diferentes discursos, inclusive o próprio, desenvolvendo a capacidade de avaliação dos textos". Dentro desse objetivo, porém, aparece ainda a concepção de língua como código e como transmissão do pensamento, ou seja, nele é tangida a ideia de transparência da linguagem: inferindo as possíveis intenções do autor marcadas no texto. Apesar disso, quando elencam os conteúdos sobre o uso da linguagem, os PCN apontam a concepção de leitura como produção de sentidos, como se depreende do recorte abaixo (BRASIL, 1998, p. 35): 
Os conteúdos das práticas que constituem o eixo USO dizem respeito aos aspectos que caracterizam o processo de interlocução. São eles:

1. historicidade da linguagem e da língua;

2. constituição do contexto de produção, representações e mundo e interações sociais:

. sujeito enunciador;

. interlocutor;

. finalidade da interação;

. lugar e momento de produção.

3. implicações do contexto de produção na organização dos discursos: restrições de conteúdo e forma decorrentes da escolha dos gêneros e suportes.

4. implicações do contexto de produção no processo de significação:

. representações dos interlocutores no processo de construção dos sentidos;

. articulação entre texto e contexto no processo de compreensão;

. relações intertextuais.

Assim, os PCN trazem referências de leitura, ainda que pouco esclarecedoras para a necessidade do professor, como prática de produção de sentidos, orientação que será reforçada pelos documentos nacionais de gestão da aprendizagem GESTAR II (2006) e GESTAR II/Guia Geral (2008).

Como se pode depreender, os PCN e, por conseguinte, o RC-TO elegem objetos linguísticos e modos parciais de abordagem desses conteúdos, às vezes persistindo em equívocos, apontando ao professor o que vale e o que não vale perpetuar no ensino de língua portuguesa. Além disso, criticam o ensino tradicional e instigam o professor a pensar novos modos de tratar seu objeto de ensino com sugestões muito genéricas, pois direcionadas a um profissional que se debate em busca de criatividade e dinâmica de sala de aula, que dê conta das exigências contemporâneas de seu ofício, sendo que a maior referência, e a mais cristalizada, que possui para o exercício de sua profissão lhe foi dada enquanto sujeito-aluno antes da graduação. Se a graduação não o 
despertou para novas formas de atuação e de tratamento do conteúdo selecionado e a FC pouco consegue ou não consegue efetivamente desestabilizar crenças e práticas ineficientes, a atuação segura e mais eficaz do professor em seu espaço profissional pode continuar, por maior tempo, ainda comprometida ou limitada.

$\mathrm{Na}$ perspectiva da $\mathrm{AD}$, sempre estamos assujeitados a discursos que nos constroem no curso da vida, ora mais, ora menos, isto é, ora mais a uma rede discursiva, ora mais a outra; ora dando voz a uns e silenciando outros, ora parecendo filiarmo-nos a discursos mais remotos, ora aos mais atuais. Isso porque, ao tomarmos a palavra, as condições de produção do discurso nos constrangem à negociação com esse emaranhado de vozes que povoam nossas mentes. Em vista dessa diversidade de vozes, melhor dizendo, desses diferentes papéis, ou posições-sujeito, que assumimos ao enunciar, o contraditório, em nossos discursos, transparece em nossas identidades; por isso, não são estáveis.

Apesar do assujeitamento que nos domina tacitamente, nessas fronteiras interdiscursivas, sempre é possível o afloramento de sentidos outros, que podem ser acolhidos ou rechaçados por nossos interlocutores. Isso nos levará a repetir essa prática com os outros ou a resistir a elas com os outros, nos embates discursivos que põem em jogo as relações de poder, permitindo-nos outro modo de assujeitamento (menos passivo), posto que efetivado por um modo de adesão em que a reflexão opera resistências e reelaboração de posicionamentos, de forma não alienada, ou menos alienada. Em vista disso, neste trabalho, é necessário refletir como essas práticas de leitura podem ter sido vivenciadas pelo docente, no Tocantins. Para isso, em seção mais à frente, alguns questionamentos serão propostos e discutidos, considerando-se possíveis práticas desde sua FI até o momento presente, na FC, que, presumimos, é efetivada com o propósito de ajudar a reconfigurar a atuação do professor, sempre em busca de atualização, modernização e/ou superação no seu trabalho com a linguagem. 


\section{CONCEPÇÃO DE LEITURA DA PESQUISADORA}

O ensino de leitura, numa perspectiva discursiva, considera que os efeitos de sentido são condicionados pelas condições de produção da leitura e que estas são afetadas pelas formações discursivas, pelas forças ideológicas, do sujeito-leitor. A título de exemplificação aos docentes da escola básica que porventura vierem a ler este artigo, descreveremos brevemente uma aula de leitura e produção de texto, para calouros do período noturno, na universidade onde trabalhamos. Os alunos leram e comentaram um texto que versava sobre o caráter das personagens do filme As pontes de Madison (EASTWOOD, 1995). Depois disso, assistiram ao filme para fazer novo comentário. O filme narra a descoberta pósmorte, pelos filhos, dos conflitos de uma mulher casada (Francesca, interpretada por Meryl Streep) que se envolve numa relação extraconjugal com um fotógrafo (Robert, interpretado por Clinton Eastwood) de uma renomada revista, recém-chegado à sua localidade rural à época. Francesca que, em vida, conseguiu manter a relação toda em segredo, tanto para os filhos como para o marido, teve de optar silenciosamente entre permanecer com o marido (que a amava) por causa também dos filhos ou ir embora com o amante, por quem estava fortemente apaixonada, sendo plenamente correspondida. Optou pela primeira alternativa.

No texto escrito, o autor do comentário sobre o filme, através de questionamentos, provoca constantemente o leitor a se posicionar sobre o que teria levado Francesca a trair o marido. Seria Robert mais um aventureiro ou apenas um romântico? Francesca foi inconsequente ou mártir da situação? Enfim, são várias as reflexões que o autor do comentário sobre filme propõe ao leitor, sem, contudo, se posicionar claramente, conforme apontaram os alunos, em sua maioria (eles queriam ouvir/ler/saber a opinião do comentarista, talvez para balizar a própria interpretação).

Os alunos (tanto homens como mulheres) mais religiosos foram taxativos em traçar um perfil bastante negativo de Francesca e de Robert, culpando principalmente Francesca pelos rumos dos acontecimentos. As 
mulheres de posicionamento político mais libertário ou que não estavam satisfeitas com seu casamento foram as que mais defenderam Francesca. Dizemos isso com base no andamento das discussões, que permitiram que algumas alunas esboçassem questões pessoais, levando-nos a perceber de que lugar social elas enunciavam, e que ideologias, impregnadas em suas FD, orientavam seus posicionamentos. Os homens que defenderam Francesca foram poucos em relação aos que, dominados pela ideologia machista, elogiaram bastante Robert, por não ter perdido a oportunidade de "pegar quem deu mole". Ao assistir ao filme, houve flexibilidade no posicionamento de uns e reposicionamento de outros, em relação ao que leram e ao que assistiram.

Comparando a leitura do filme com a leitura do texto escrito, resguardadas as devidas diferenças, vejamos o que os posicionamentos antagônicos dos leitores, acima, revelam. Primeiro, mostram que os efeitos de sentido, produzidos pela leitura (assistência) de um filme, divergem e podem também ser comparáveis, em muitos aspectos, à interpretação de um texto escrito, ou seja, a análise das personagens, filtrada por diferentes enunciadores, a partir do autor do texto escrito, foi diferente, em relação ao percebido através do filme. Segundo, as formações discursivas, as ideologias dominantes no sujeito-leitor condicionaram seu posicionamento, em relação ao comportamento das personagens, isto é, favoreceram um tipo de olhar/percepção/sensibilidade/sentido e não outro.

Evidentemente, tudo isso não passa de uma sintetização do que ocorreu na aula. Não desenhamos o quadro completo das leituras ocorridas, o que aqui nem seria possível, dos diversos comentários, das diferentes vozes que apareciam nas falas dos alunos. Não obstante, acreditamos que essa pequena mostra pode desanuviar, para muitos professores da escola básica, alguns pontos sobre leitura como produção de sentidos, ou seja, leitura numa perspectiva discursiva, apontando, como enfatiza Cazarin (2006, p. 302) ao explicitar a tese pêcheuxtiana sobre essa questão, que ler implica inscrever-se numa disputa de interpretações. 
Além disso, não cabia à Pesquisadora, como professora, determinar sentidos (mesmo vendo-se a isto tentada) para a leitura do texto escrito, nem para a leitura do filme (texto cinético audiovisual), através de perguntas fechadas. Tais perguntas, meramente decodificativas ou não, trazem, embutidas, expectativas afuniladas para certas respostas, como, muitas vezes, é feito por certos LD. Muitos professores do ensino básico, que internalizaram a forma cristalizada de ler e de ensinar a ler do LD tradicional, têm a tendência de, também, agir dessa forma, tolhendo a possibilidade de leitura plural de um mesmo texto.

O que cabia à Pesquisadora, como coordenadora dessa ação naquele espaço, era provocar e questionar a leitura dos alunos, favorecendo a fluidez de sentidos. Para isso, foi necessário avançar (ou restringir a ação/atividade), na sequência, para questionamentos sobre marcas textuais e discursivas que estavam a suscitar sentidos, que apareciam na leitura dos alunos. Tal ação, sem dúvida, pode ser vista como uma forma de delimitação e de legitimação de certas leituras (interpretações) em relação a outras. Porém, ela também ajuda a balizar, através dos elementos textuais, visíveis no texto escrito, a interpretação do filme (um texto audiovisual).

Caso o objetivo da aula da professora fosse, também, usar o texto como pretexto para estudar a estrutura de uma narrativa de texto escrito e/ou de texto cinético (o que entendemos não ser o problema do ensino), questões pertinentes a este saber poderiam entrar categoricamente, isto é, até deveriam entrar. No entanto, a leitura plural, acima descrita, faz-se necessária, para que o texto não se perca, isto é, para que o texto não se esvazie de sua função essencial, que é o embate ideológico. É esse embate que gera o texto, no momento da leitura, ou seja, ao ser lido, as perguntas suscitadas pelo(s) leitor(es) produzem o texto, no verdadeiro sentido da palavra "produzir" (= criar, fazer existir, gerar).

No entanto, na sala de aula, em geral, os textos "lidos" são usados de outra forma, como meros pretextos para objetivos secundários, dissociados do objetivo maior que opera a emergência de um texto. A questão problemática que se impõe, a nosso ver, é que os objetivos 
secundários do uso de textos na escola básica (texto apenas como pretexto para atividade/conteúdo limitado) acabam por eliminar o processo discursivo, que envolve autor, leitor e texto, implicados nas condições de produção do processo. Esse processo implica produção de sentidos, com tomada de posição do autor e do leitor ante as vozes que os provocam nos embates discursivos, o questionamento das ideologias, que perpassam os textos, etc. É isso que contribuirá para ampliar a visão de mundo do estudante; é o que o ajudará a se tornar positivamente mais crítico em relação a si, aos outros e a tudo que o cerca; dando sentido a seu esforço intelectual para se envolver com as vozes alheias. Impedir esse tipo de prática discursiva de leitura gera insatisfação a todos os envolvidos com o texto, seja o aluno, seja o professor, e até mesmo o autor do texto (caso esteja presente).

$\mathrm{Na}$ escola, o engessamento em nossas aulas de leitura (e de escrita) elimina o prazer da leitura crítica (e cria barreiras quanto à produção escrita). É por isso que muitas pessoas, que passaram ou que passam pela escola, também, não gostam de ler (nem de escrever). Justificam-se, dizendo (talvez até repetindo o que ouviram de ex-professores) que não sabem ler, não aprendem a ler e têm horror às aulas de português (engrossando a lista de analfabetos funcionais ${ }^{3}$ na sociedade).

Evidentemente, a ideia de estar preparado (ou de preparar alguém) para ler plenamente qualquer texto é uma questão para ser discutida holisticamente. Isso porque a questão implica inúmeras variáveis que se atravessam ou que se complementam. Cada texto, por exemplo, em cada época, pode ter uma leitura mais ou menos orientada e/ou aceita. Mediante isso, surgem perguntas que afetam (possibilitam ou impedem) um preparo desse porte: o que significa ler plenamente? Quem tem autoridade para legitimar determinadas leituras em determinados assuntos? Como se pode ler determinado texto em determinadas circunstâncias? As respostas implicam variáveis, cuja relevância, cada

\footnotetext{
3 Entenda-se por analfabetos funcionais cidadãos alfabetizados, inclusive com diploma, que não conseguem entender mínima ou razoavelmente o que leem nem produzir, por escrito, enunciados quer curtos, quer pouco mais extensos que tematizem assuntos genéricos, ainda que do senso comum e mesmo quando os assuntos thes sejam bem mais familiares.
} 
uma de per si, mobiliza, nos interlocutores que discutem o assunto, crenças e questões teóricas de caráter cognitivo, linguístico, sociológico, filosófico, religioso etc., o que não é a discussão em foco, pois estamos falando do ensino básico, com vistas a um letramento do tipo ideológico (e não autônomo).

Nessa perspectiva, o leitor carece de liberdade para comentar, avaliar, discutir o texto (temática, posição ideológica, estilo etc.), posicionando-se discursivamente. O leitor não deveria ser tolhido; importa evitar questionamentos irrelevantes, como mero trabalho de decodificação, que provoque o desinteresse dos leitores. Justificando o uso destacado aqui da palavra liberdade, é necessário lembrar que discursivamente ela não é tomada de forma igual na prática de sala de aula. Ora, se a cada palavra enunciada formações discursivas e ideológicas específicas são mobilizadas para interpretá-la, considerando a posição-sujeito que a enuncia e/ou à qual ela se refere, decerto que, na sala de aula, a liberdade de interpretação do professor não é a mesma oferecida ao aluno ou por este reclamada, dadas as relações de força, geralmente assimétricas, que se instauram nessas enunciações.

A leitura como processo, e não como um mero produto da decodificação, é um fenômeno complexo, ou seja, implica fatores de diversas ordens, dependendo da perspectiva pela qual é tratada. Os livros didáticos (LD), na tentativa de atender aos dispositivos teóricos de documentos oficiais, como os PCN, têm passado por um processo de constante (re)avaliação (BUNZEN; ROJO, 2005; SANTOS, 2001), por se saber que eles contribuem para a cristalização de estratégias de leitura. Daí seria talvez desnecessário dizer que ensinar a ler um texto, na escola básica, acaba refletindo muito o tipo de abordagem prejudicial e naturalizada que muitos LD desenharam, ou que ainda desenham, principalmente se o professor não for ousado o suficiente para soltar, mesmo que por alguns momentos, o texto das amarras das perguntas que o seguem, principalmente quando estas são improdutivas, ou seja, quando estas não instigam aprofundamento ao se olhar o texto. 
Assim, ao discutir os tipos de perguntas feitas em LD, Santos (2001) não censura, por exemplo, os tipos de perguntas chamadas subjetivas, consideradas problemáticas, para alguns avaliadores, por estarem centradas mais no sujeito-leitor que propriamente no texto. Considera que esse é um dos tipos que bem pode evidenciar leitura como produção de sentidos, ou seja, leitura como relação entre sujeitos (leitor/enunciadores), leitura como efeito de sentidos entre locutores.

\section{DA LEITURA COMO EFEITO DE SENTIDOS E SUA ABORDAGEM NA FORMAÇÃO DOCENTE}

Reiterando a fala de muitos docentes da escola básica e da área acadêmica, reafirmamos que não é fácil fazer certas transposições didáticas, mesmo que o profissional seja engajado, aplicado, imbuído do desejo de efetivar práticas mais satisfatórias, como o são, por exemplo, nossos sujeitos de pesquisa. Além do mais, sabemos que reproduzimos o discurso oficial, às vezes tacitamente, outras com maior reflexão, até como forma de legitimar nossa função como professores, mesmo (sabendo) que ainda não o tenhamos incorporado à prática, efetivamente, ou que o rejeitemos em parte, por razões específicas (às vezes nem mesmo claras para nós).

A reflexão acima denuncia, todavia, que nem sempre somos meros papagaios, como bem observa Possenti (2004, p. 107), ao nos chamar a atenção para a sutileza semântica entre o determinar e/ou o condicionar o dizer, que as condições de produção do discurso operam durante a enunciação. Daí, questionarmo-nos sobre como o dizer inesperado, não previsto para a posição-sujeito que enuncia, é/foi trabalhado na graduação de nossos sujeitos-informantes.

Levantamos alguns questionamentos para o silenciamento no discurso e na prática de docentes do ensino básico no Tocantins, para a leitura como produção de sentidos:

a) Que situação empírica nossos informantes efetivamente tiveram, ou têm, de leitura como produção de sentidos? 
b) $\mathrm{Na}$ graduação, os docentes permitiam, a esses futuros professores, sentidos não autorizados pelos textos/assuntos lidos/“discutidos", em aula?

c) Como os futuros professores eram silenciados ou como os sentidos divergentes que produziam, ou viam produzidos por colegas, eram negociados em classe?

d) Eles tinham voz nessa arena discursiva? Até que ponto?

e) Como essa voz era negociada? Como eram censurados quando seu posicionamento ou interpretação ia de encontro à leitura que o docente da graduação orientava/pretendia?

f) Enquanto graduandos, a que tipo de discussão, debate, embate, polêmica, aula, eles foram expostos?

g) Atualmente, como é dada voz aos professores, nos encontros de FC? As noções de certo e errado, tão criticadas no ensino de língua, vicejam ou são modalizadas no espaço das discussões da FC? De que forma?

h) Os professores têm direito de "errar" (destoar do que é privilegiado/esperado), ou melhor, de também acertar errando em seus posicionamentos durante cursos e encontros de formação? Como a leitura não autorizada é rechaçada ou acolhida nos encontros/cursos de FC?

i) A que tipo de concepção de leitura os professores vivem ainda hoje expostos, na prática, durante os encontros e cursos de FC? Como se chega a um consenso de leitura (esperada) nesse espaço? Como as outras leituras são afloradas ou reprimidas?

j) Como a FC problematiza essas questões junto aos professores? A que referenciais práticos de leitura (e escrita) os coordenadores, orientadores, professores e/ou supervisores expõem os professores durante as FC?

Sabemos que as perguntas acima parecem redundantes, mas o são propositalmente. Elas visam a possibilitar o afloramento da autorreflexão, tanto dos professores pesquisados e colegas, como, e principalmente (se possível), dos professores universitários que os 
formam, dentro ou fora do Tocantins, considerado até o momento de baixa produtividade escolar, mormente nas áreas de leitura/escrita.

Além disso, talvez estejamos, com esse questionamento prolixo, apontando, ou (re)lembrando, que o círculo vicioso de resultado de pesquisas, que tanto descrevem ou acusam a cristalização e/ou a permanência de práticas de leitura apenas, ou mais, como decodificação, é reflexo da busca (ou da defesa) de uma prática que não foi privilegiada no espaço onde mais ainda deveria aflorar, durante a formação inicial dos professores. Entendemos, outrossim, que ler as linhas, as entrelinhas e além destas, como define Silva (1998), o processo de formação do leitor crítico, é ensinado não apenas com discursos teóricos, mas com práticas, resultando em conhecimento empírico.

Quanto à formação dos professores de LM, no estado de Tocantins, surgem vários fatores condicionantes, que poderiam num certo sentido justificar práticas de leitura como decodificação. Se a graduação pouco favoreceu esse tipo de interlocução, em que o absurdo aparece, se lá a aula é/foi mais um monólogo (só o docente fala/falou) que uma prática dialógica, como defende Bakhtin (1997) no processo interacional de comunicação; se na oralidade não há/houve espaço para a vOz discordante dos, então, alunos-futuros-professores, nem para a leitura absurda, não prevista pelo docente; se só sua leitura [do docente] é/foi permitida, compreende-se melhor, inclusive, a avalanche de trabalhos acadêmicos da graduação mais com perfil de cópia que de reelaboração e posicionamento diante das vozes com as quais o alunoleitor-futuro-professor dialoga.

Em tais condições, uma prática desfavorável ao ensino de leitura levaria a uma visão de linguagem com efeito de transparência e de leitura com sentido único. Não se trata aqui de apelo a uma prática de superinterpretação (ECO, 1993), isto é, de uma liberdade excessiva para o leitor interpretar o texto como lhe convier, estimulando-se $n$ interpretações através da superinterpretação ad infinitum. A superinterpretação desconsidera a negociação necessária entre aspectos centrais e marginais no texto, legitimando leituras não autorizadas pelo grupo social. 
Seria necessário, no entanto, verificar, neste caso questionar, até que ponto a defendida perspectiva discursiva de leitura é privilegiada, na prática, no espaço da Universidade. Quando ela é permitida, a superinterpretação e/ou a leitura absurda também ocorrem, mesmo que surjam para ser refutadas ou, pelo menos, discutidas. A questão central é a forma como são refutadas, ou seja, como se negociam as diversas leituras que surgem, quando se admite o florescimento do múltiplo, do heterogêneo, ou como se prestigiam/autorizam as leituras mais convincentes à maioria do grupo de leitores, envolvidos no processo.

O que também se põe em questão aqui, além da metodologia de abordagem de texto, é a postura do docente em posição privilegiada, que acata ou descarta, educadamente ou de modo autoritário, o que é essencial no processo de leitura como produção de sentidos. Se o aprendiz, futuro-professor, é ensinado, seja qual for o nível (básico, graduação, especialização etc.), através da intimidação, a só falar o previsível, melhor dizendo, a tomar a palavra apenas quando for capaz de enunciar reiterando a leitura do docente, assujeitando-se (tacitamente) a esse modo de relação de poder, mais facilmente transplantará isso para sua sala de aula, seja com crianças, seja com jovens, seja com adultos. Esse comportamento não favorece, a nosso ver, uma pedagogia de ensino/aprendizagem saudável, que carece de peculiar liberdade e respeito pelo esforço intelectual do aprendiz, para efetivar o processo educacional de forma mais humana. A não ser que, reflexivamente, o aprendiz (futuro-professor) consiga rebelar-se contra esses modos, por vezes desumanos, de coerção didática, evitando sua reiteração nos diversos níveis de ensino. Se isso não ocorre, o círculo vicioso de metodologia e de posturas equivocadas em relação ao ensino/aprendizagem permanecerá dificultando o fluxo da tão almejada educação de qualidade.

Entendemos que é essa possibilidade de florescimento do inesperado, do equívoco, e esse modo de negociação entre o pertinente e o impertinente que vão dar a referência prática, ao professor em formação, sobre o processo de leitura como produção de sentidos. $\mathrm{Ou}$ seja, ele também estaria preparado para ouvir as leituras avessas de seus 
alunos, daria certa liberdade a eles para pensar a fim de que surjam outras/novas leituras, inclusive as mais afinadas com as marcas textuais. Teria mais respeito pelo esforço intelectual de seu aluno. Não ficaria, assim, exigindo, esperando ou orientando uma leitura única e igual de todos os alunos, validada pelo autor do LD que segue, ou por sua própria leitura, como professor.

Por conseguinte - aqui reforçamos -, realidades como essas não mudarão apenas com a massificação de leituras teóricas sobre a leitura como produção de sentidos, para que se perceba apenas o efeito papagaio da repetição mecânica ou, no máximo, o efeito parafrástico da repetição técnica do discurso oficial. É necessário desenvolver práticas efetivas de leitura como produção de sentidos, desde a graduação, que se mantenham também na FC, e não apenas com reflexões teóricas sobre a questão, sem que o referencial seja sua efetivação nos cursos de FI e encontros/cursos de FC, como amostragens do discurso na prática por aqueles que tanto a defendem.

A AD chama a atenção para uma questão crucial, nesse aspecto: a ideologia, que se materializa no discurso, é vista como resultado de práticas que as reforçam ou as desestabilizam, conforme a posiçãosujeito ao enunciar. Explicando melhor: há professores que são capazes de listar mnemonicamente as orientações dos PCN para o ensino de LM. Apesar disso, não são capazes de colocar em prática o que o documento sugere, mesmo que com ele concorde. Ora, se nunca, pouco, ou mal vivenciou tal prática, no máximo saberá repetir o que a voz de autoridade manda, mas pouco saberá efetivamente realizar concretamente.

\section{CONSIDERAÇÕES FINAIS}

Entendemos que a discussão aqui encaminhada não é resposta definitiva à solução do problema discutido, pois complexo, porém, cremos que ela aponta e/ou ecoa possíveis causas - e, consequentemente, algumas sugestões exequíveis de intervenção - para efeitos negativos ainda muito presentes nas aulas de leitura, que ultrapassam os limites da sala de aula do ensino obrigatório (ensino 
básico). Desse modo, tanto a FI quanto a FC do docente desse nível de ensino têm a responsabilidade de assumir sua parcela de contribuição na pouca compreensão que muitos professores demonstram sobre noções tão em voga no discurso oficial da atualidade, mesmo tendo sido os PCN produzidos há mais de uma década. Tal assunção pode produzir mais fortemente ações e reformulações metodológicas nos cursos e encontros, quer da FI, que da FC, na busca de reverter quadro tão questionado, pois se tem tentado, muitas vezes, materializar na prática o discurso da cidadania, sem, no entanto, dar aos sujeitos de classes menos favorecidas acesso ao usufruto do direito de pensar, agir e participar ativamente das decisões que o afetam, direta ou indiretamente, na comunidade micro ou macro da qual participa, por meio de seu patrimônio maior: a linguagem. Afinal, o desenvolvimento da competência discursiva para o exercício da cidadania é um processo de formação que cobre todos os ciclos do ensino sistematizado e legitimado socialmente, isto é, instaura-se da alfabetização à pós-graduação.

\section{REFERÊNCIAS}

BAKHTIN, M. Estética da criação verbal. Tradução de $M^{a}$ Ermantina G.G. Pereira. 2ed. São Paulo: Martins Fontes, 1997.

BRASIL. Parâmetros Curriculares Nacionais. Língua portuguesa: ensino fundamental II. Brasília/Secretaria de Educação Fundamental: MEC/SEF, 1998.

Programa gestão escolar da aprendizagem escolar - Gestar II. Guia Geral. Brasília: Ministério da Educação. Secretaria de Educação Básica, 2008, 76p.

Programa gestão da aprendizagem escolar II: língua portuguesa. v.1. Brasília: Fundo escola/DIPRO/FNDE/MEC, 2006.

BUNZEN, C.; ROJO, R. Livro didático de língua portuguesa como gênero do discurso: autoria e estilo. In: COSTA-VAL, M. G.; MARCUSCHI, B. (Orgs.).

Livros didáticos de língua portuguesa: letramento e cidadania. Belo Horizonte: Ceale; Autêntica, 2005. p. 73-118.

CAZARIN, E. A. A leitura: uma prática discursiva. Linguagem em (Dis)curso, Tubarão, v. 6, n. 2, p. 299-313, maio/ago. 2006. 
CORACINI, M. J. Pergunta-resposta na aula de leitura: um jogo de imagens. In: CORACINI, M. J. (Org.) O jogo discursivo na aula de leitura (língua materna e língua estrangeira). Campinas: Pontes, 1995. p. 75-84.

- O livro didático nos discursos da Lingüística Aplicada e da sala de aula. In: CORACINI, M. J. (Org.). Interpretação, autoria e legitimação do livro didático. Campinas: Pontes, 1999, p. 17-31.

EASTWOOD, C. As pontes de Madison/The Bridges of Madison County. [Filme/video]. Direção de Clinton Eastwood. EUA, 1995. DVD, 135 min. Drama.

ECO, U. Interpretação e superinterpretação. Martins Fontes, 1993.

MOITA LOPES, L. P. Padrões interacionais em sala de aula de Língua Materna: conflitos culturais ou resistência. In: COX, M. I.; ASSIS-PETERSON, A. A. de. Cenas de sala de aula. Campinas: Mercado das Letras, 2001. p. 161-179.

ORLANDI, E. P. Discurso e leitura. 3. ed. Campinas-SP: Editora da Unicamp, 1996.

POSSENTI, S. Os limites do discurso - ensaios sobre discurso e sujeito. 2.ed. Curitiba: Criar Edições, 2004.

SANTOS, J. S. As perguntas de compreensão nos livros didáticos uma e três estrelas: quais os avanços? 2001. 131 f. Dissertação (Mestrado em Linguística Aplicada). Programa de Pós-graduação em Linguística Aplicada, Universidade Estadual de Campinas, Campinas, 2001.

SILVA, E. T. Criticidade e leitura: ensaios. Campinas-SP: Mercado de Letras: Associação de Leitura do Brasil, 1998.

SILVA, W. R.; MELO, L. C. Teoria acadêmica e prática docente em referencial curricular. In: SILVA, W. R.; MELO, L. C. Pesquisa e ensino de língua materna e literatura: diálogos entre formador e professor. Campinas-SP: Mercado de Letras; Araguaína-TO: Universidade Federal do Tocantins-UFT, 2009, p.37-62.

TOCANTINS. Referencial Curricular do Ensino Fundamental das escolas públicas do Estado do Tocantins: Ensino Fundamental do $1^{\mathrm{o}}$ ao $9^{\mathrm{o}}$ ano. $2^{\mathrm{a}}$ Edição / Secretaria de Estado da Educação e Cultura - TO: 2008. 281 p. 
Recebido em: 03/10/11. Aprovado em: 19/04/12.

Title: Reading in a discursive perspective in the educational formation: some questions Author: Janete Silva dos Santos

Abstract: Based on the conceptual framework of Discourse Analysis, this work discusses, through raising some questions, the reading practice, in a discursive perspective, in the formation of teachers' who work in the state of Tocantins; in other words, this work reflects on reading as the effect of meanings, according to the theoretical presuppositions of the Discourse Analysis $(D A)$ of the French line. The intention in the present text, more than to contribute to the debate on that issue, is to point some obstacles in the initial formation (IF), or in the continuous formation (CF) of the teachers in the basic level that may be making difficult their understanding of the National Curricular Parameters (PCN) and, consequently, their poor understanding of the Curricular Referential for the State of Tocantins (RC-TO), in relation to the teaching/learning of reading in a more flexible perspective, which takes into account the production conditions in an including context.

Keywords: Discourse. Reading and teaching. Teacher education. PCN and RC-TO.

Titulo: Lectura en una perspectiva discursiva en la formación docente: algunos cuestionamientos Autor: Janete Silva dos Santos

Resumen: Con base en los supuestos teóricos del Análisis del Discurso, este trabajo discute, a través de algunos cuestionamientos, la práctica de lectura, en una perspectiva discursiva, en la formación del profesor que actúa en el estado de Tocantins, o sea, refleja sobre la lectura como efecto de sentidos, conforme supuestos teóricos del Análisis del Discurso (AD) de linea francesa. El objetivo en el presente texto, más que contribuir con el debate sobre la cuestión, es apuntar algunos obstáculos en la formación inicial (FI) o formación continuada (FC) de profesores de la enseñanza básica que puedan baber causado su poca comprensión sobre lo que sugieren los Parámetros Curriculares Nacionales (PCN) y, por consiguiente, el Referencial Curricular de Tocantins (RC-TO), en relación a la enseñanz̧a/ aprendizaje de lectura en una perspectiva más flexible, que lleva en cuenta las condiciones de producción en un contexto más abarcador.

Palabras-clave: Discurso. Lectura y enseñanza. Formación docente. PCNy RC-TO.

SANTOS - Leitura numa perspectiva discursiva 